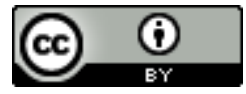

Esta obra está sob o direito de Licença Creative Commons Atribuição 4.0 Internacional.

\title{
VANTAGENS E DESAFIOS DO USO DAS TECNOLOGIAS NA GESTÃO ESCOLAR
}

\author{
Ivaldo Sales Nascimento Júnior ${ }^{1}$ \\ Eduardo Cabral da Silva
}

\section{RESUMO}

O diretor escolar desempenha um importante papel para o funcionamento desta, estando capacitado para promover a integração do setor administrativo e pedagógico. A introdução de tecnologias na escola promove a transformação deste espaço em uma organização mais proativa e moderna que se atualiza constantemente, estabelecendo-se um processo reflexivo e constante da prática educativa. $\mathrm{O}$ objetivo deste artigo foi determinar os principais desafios e benefícios pertinentes ao uso das diversas tecnologias pelas escolas, no aprimoramento da sua gestão no ambiente escolar. Trata-se de uma revisão sistemática da literatura, onde a busca foi realizada na base de dados Scielo, utilizando-se como descritores Tecnologias e Gestão escolar, publicados no período de 2010 a 2020. Foram encontrados 12 artigos, que após aplicação dos critérios de inclusão e exclusão foram reduzidos a 05 artigos, que analisados resultaram na formulação de duas categorias. Evidenciou-se a existência de importantes desafios para a implantação eficiente das tecnologias no ambiente escolar, assim como algumas vantagens, seja ela qual for, especialmente quando estas são direcionadas à gestão, observando-se uma importante escassez de artigos sobre o tema, assim como a necessidade de se investir em formação continuada dos professores e gestores para a implantação das tecnologias alinhadas a uma prática pedagógica reflexiva e ativa.

Palavras-chave: Tecnologias. Desafios. Benefícios. Ambiente escolar.

\footnotetext{
1 ivaldosalesjunior@bol.com.br

2 edcs.cabral@gmail.com
} 


\section{INTRODUÇÃO}

O diretor de uma escola desempenha um importante papel para o funcionamento desta, tendo-lhe como atribuições a gestão financeira, administrativa e pedagógica da escola, sendo a entidade máxima na gestão escolar, assumindo uma posição de destaque em todas as áreas administrativas, o que inclui as relacionadas à integração educativa das tecnologias (PIEDADE; PEDRO, 2014).

Para Fonte (2004) um gestor na plenitude de seu trabalho está capacitado para promover a integração do setor administrativo e pedagógico no ambiente escolar, por meio do uso das TICs que dinamizam as trocas de informações, assim como as decisões a serem tomadas e o acompanhamento das atividades administrativas e pedagógicas da escola, podendo ter condições para promover estudos, discussões e decisões, sendo tomadas conjuntamente em um processo reflexivo e constante da prática educativa.

Para Moran, Masetto e Behrens (2003), a introdução de tecnologias na escola promove a transformação deste espaço educativo em uma organização mais proativa e moderna que se atualiza constantemente.
Todavia, o uso de tecnologias no ambiente educacional, ainda nos dias de hoje, apresenta-se como um importante desafio a ser superado, pois, conforme a visão de Moraes (2000), não basta obter recursos para serem utilizados na escola como: televisão, videocassete, computadores, etc, sem que estes estejam acompanhados de uma transformação na formação e comportamento do professor.

Apesar da diversidade tecnológica existente em nossa sociedade, que se apresenta como algo positivo, é importante destacar que a grande maioria das escolas, assim como importantes segmentos da nossa sociedade, não têm conseguido acompanhar este acontecimento por diversos fatores limitantes.

A este respeito, Fadel et al. (2014) inferem que o desenvolvimento tecnológico tem avançado a passos largos, mas o mesmo não tem se aplicado à educação, de modo que a escola precisa priorizar a diminuição desta grande diferença.

Assim, o objetivo deste artigo foi determinar os principais desafios e benefícios pertinentes ao uso das diversas tecnologias pelas escolas, no aprimoramento da sua gestão no ambiente escolar. 


\section{MÉTODOLOGIA}

A metodologia adotada para a realização da presente pesquisa foi revisão sistemática da literatura, por meio da busca sistematizada de informações com o uso de descritores, constituído por cinco etapas: elaboração da pergunta, coleta de dados, avaliação destes, análise e interpretação dos dados, seguido da apresentação dos resultados e considerações finais.

Tendo em vista a relevância do uso das tecnologias no ambiente escolar, compreendendo o espaço físico, os seus atores e sua função social, torna-se imperiosa a elaboração do seguinte questionamento: Quais os benefícios e desafios enfrentados pelos gestores escolares quanto ao uso das tecnologias no ambiente escolar?

Foi utilizada para a realização da referida pesquisa, a Biblioteca Eletrônica Científica Online (Scientific Electronic Library On line - SciELO). Utilizou-se como estratégia de busca os termos “ Tecnologias" and "Gestão Escolar" que nortearam a busca, sendo utilizados como filtros: artigos publicados e disponíveis na íntegra, no idioma português, no período de 2010 a 2020.

\section{RESULTADOS E DISCUSSÕES}

O presente estudo teve como resultado 05 artigos por atenderem a
Seguindo esta ordem, a pesquisa resultou no total de 12 artigos. Os artigos encontrados tiveram seus títulos e resumos analisados, sendo adotados os critérios de exclusão: publicações em outros idiomas, artigos incompletos, não relacionados às tecnologias e a gestão escolar e duplicados na base de dados. Nesta etapa foram excluídos 07 artigos, resultando em um total de 05 artigos (figura 1).

Figura 1- Fluxograma demonstrativo da pesquisa.

Artigos relevantes identificados na busca inicial

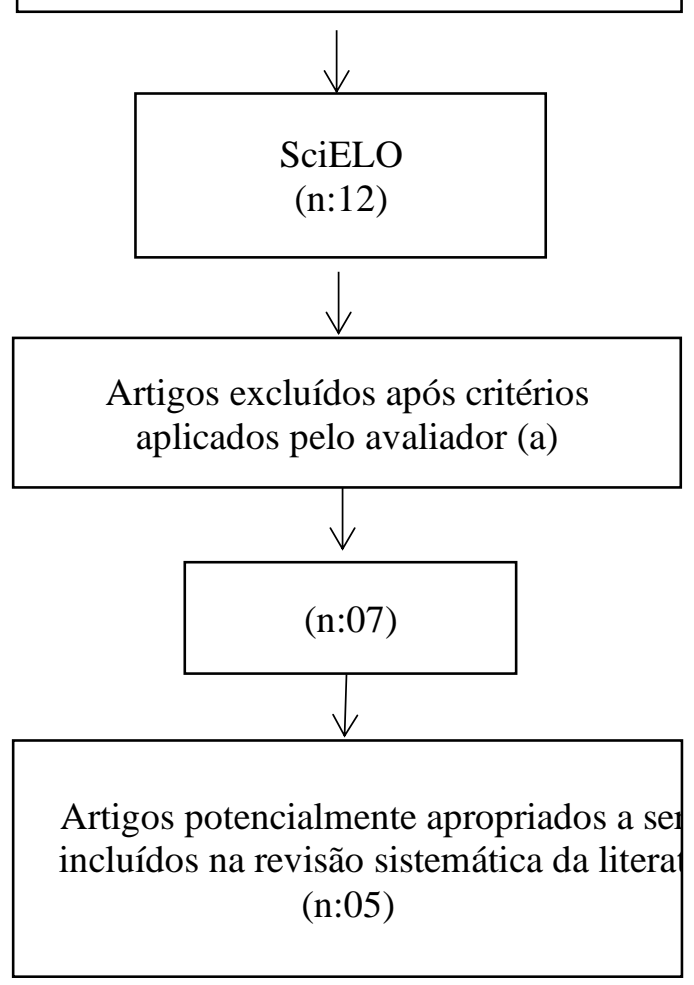

Fonte: Próprio autor.

questão norteadora do estudo. Estes artigos tiveram seus dados registrados, tais como: título, ano de publicação, autores, objetivos, 
metodologia, resultados e conclusões

(Quadro 1). 
Quadro 1- Quadro sinóptico dos artigos selecionados para a revisão sistemática da literatura.

\begin{tabular}{|c|c|c|c|c|c|c|}
\hline $\mathbf{N}$ & TÍTULO & ANO & AUTORES & OBJETIVOS & TIPO DE PESQUISA & CONCLUSÃO \\
\hline 1 & $\begin{array}{l}\text { Obstáculos } \\
\text { emergentes da } \\
\text { prática de ensino com } \\
\text { a investigação } \\
\text { matemática. }\end{array}$ & 2020 & $\begin{array}{l}\text { WICHNOSKI, } \\
\text { Paulo. }\end{array}$ & $\begin{array}{l}\text { Interrogar os fatores que se } \\
\text { mostraram limitantes da } \\
\text { prática com a Investigação } \\
\text { Matemática segundo o } \\
\text { relatado nas produções de } \\
\text { professores que } \\
\text { trabalharam sob essa } \\
\text { perspectiva no PDE/PR. }\end{array}$ & $\begin{array}{l}\text { Estado da arte de } \\
\text { abordagem qualitativa } \\
\text { com enfoque } \\
\text { fenomenológico }\end{array}$ & $\begin{array}{l}\text { Os dados permitem afirmar que os } \\
\text { obstáculos são decorrentes das ações dos } \\
\text { sujeitos envolvidos no trabalho } \\
\text { (professores e alunos), da dinâmica e } \\
\text { características epistemológicas da } \\
\text { própria Investigação Matemática, da } \\
\text { estrutura e organização escolar e da } \\
\text { inserção das Tecnologias da Informação } \\
\text { e Comunicação (TIC) e encontram } \\
\text { explicações nas concepções e crenças } \\
\text { próprias dos professores, dos alunos, da } \\
\text { gestão escolar, da equipe pedagógica, da } \\
\text { família e do Estado, advindas da cultura } \\
\text { escolar predominante. }\end{array}$ \\
\hline 2 & $\begin{array}{l}\text { Programa Jovem de } \\
\text { futuro: uma } \\
\text { tecnologia } \\
\text { educacional do } \\
\text { terceiro setor. }\end{array}$ & 2020 & $\begin{array}{l}\text { BALDUINO, } \\
\text { Maria } \\
\text { Aparecida } \\
\text { Canale. }\end{array}$ & $\begin{array}{l}\text { Este artigo tem como foco } \\
\text { a discussão que surge nas } \\
\text { relações entre o público e o } \\
\text { privado na educação e, de } \\
\text { maneira mais específica, } \\
\text { as implicações que a } \\
\text { tecnologia educacional do } \\
\text { Programa Jovem de Futuro } \\
\text { (PJF), apresentada, criada } \\
\text { e desenvolvida pelo } \\
\text { Instituto Unibanco (IU), } \\
\text { gera na gestão das escolas } \\
\text { públicas. }\end{array}$ & $\begin{array}{l}\text { Levantamento } \\
\text { bibliográfico com } \\
\text { análise documental. }\end{array}$ & $\begin{array}{l}\text { Pode-se identificar que o PJF emprega a } \\
\text { lógica de mercado nas escolas públicas } \\
\text { de Ensino Médio e induz a } \\
\text { responsabilização das escolas pelos } \\
\text { resultados, o que incorpora alterações nas } \\
\text { suas propostas pedagógicas e, assim, } \\
\text { compromete a autonomia da gestão } \\
\text { escolar, ferindo o princípio da gestão } \\
\text { democrática. }\end{array}$ \\
\hline 3 & $\begin{array}{l}\text { Integração } \\
\text { pedagógica das TIC }\end{array}$ & 2018 & $\begin{array}{l}\text { CARLOS, } \\
\text { Vânia; }\end{array}$ & $\begin{array}{l}\text { Implementar o conceito } \\
\text { Edulab visando a adoção }\end{array}$ & $\begin{array}{l}\text { Projeto de intervenção, } \\
\text { com } \quad \text { abordagem }\end{array}$ & $\begin{array}{l}\text { Concretamente no que se refere ao } \\
\text { projeto AGIRE, houve o reconhecimento }\end{array}$ \\
\hline
\end{tabular}




\begin{tabular}{|c|c|c|c|c|c|c|}
\hline & $\begin{array}{l}\text { no contexto de um } \\
\text { Edulab - reflexão e } \\
\text { sistematização de } \\
\text { boas práticas (Projeto } \\
\text { AGIRE). }\end{array}$ & & $\begin{array}{l}\text { POMBO, } \\
\text { Lúcia; } \\
\text { LOUREIRO, } \\
\text { Maria João. }\end{array}$ & $\begin{array}{l}\text { de práticas pedagógicas } \\
\text { inovadoras e a promoção } \\
\text { da literacia digital de } \\
\text { professores (e alunos). }\end{array}$ & $\begin{array}{l}\text { qualitativa e aplicação } \\
\text { de instrumentos para } \\
\text { coleta de dados. }\end{array}$ & $\begin{array}{l}\text { de alguns progressos relativamente à } \\
\text { utilização das TIC nas salas de aula, } \\
\text { tendo os participantes iniciado o projeto } \\
\text { num nível de adoção e passando, no final } \\
\text { do projeto, para um nível mais elevado de } \\
\text { integração das TIC, o de adaptação. } \\
\text { Observou-se também que as tecnologias } \\
\text { disponibilizadas pelo projeto, quando } \\
\text { otimizadas e acompanhadas de } \\
\text { metodologias de ensino adequadas, } \\
\text { podem ser enriquecedoras do processo de } \\
\text { ensino e aprendizagem, transformando as } \\
\text { aulas em sessões mais dinâmicas, } \\
\text { eficazes e motivadoras e contribuindo } \\
\text { para aprendizagens ativas } \\
\text { significativas. }\end{array}$ \\
\hline 4 & $\begin{array}{l}\text { Programa um } \\
\text { computador por } \\
\text { aluno: o acesso às } \\
\text { tecnologias digitais } \\
\text { como estratégia para } \\
\text { a redução das } \\
\text { desigualdades } \\
\text { sociais. }\end{array}$ & 2017 & $\begin{array}{l}\text { ECHALAR, } \\
\text { Adda D. L. } \\
\text { Figueiredo.; } \\
\text { PEIXOTO, } \\
\text { Joana. }\end{array}$ & $\begin{array}{l}\text { Analisar a implantação do } \\
\text { Prouca no Brasil e no } \\
\text { Estado de Goiás, a partir } \\
\text { do tratamento da questão } \\
\text { da inclusão digital via } \\
\text { ambiente escolar como } \\
\text { resultado de políticas } \\
\text { públicas vinculadas aos } \\
\text { organismos multilaterais } \\
\text { em nosso país, os quais } \\
\text { visam à manutenção da } \\
\text { desigualdade social por } \\
\text { meio de um processo de } \\
\text { inclusão excludente. }\end{array}$ & $\begin{array}{l}\text { Pesquisa exploratória e } \\
\text { empírica, com análise } \\
\text { documental. }\end{array}$ & $\begin{array}{l}\text { Queremos demonstrar que os } \\
\text { identificados problemas e deficiências na } \\
\text { infraestrutura para a sua implantação, na } \\
\text { gestão de seus processos e na formação } \\
\text { dos professores não se constituem em } \\
\text { aspectos pontuais, mas estruturantes } \\
\text { deste Programa. Por esta razão, o seu } \\
\text { mero reajuste ou adequação não são } \\
\text { suficientes para equalizar as } \\
\text { desigualdades sociais, conforme o } \\
\text { propalado. }\end{array}$ \\
\hline 5 & $\begin{array}{l}\text { Tecnologias digitais } \\
\text { na gestão escolar: } \\
\text { práticas, proficiência }\end{array}$ & 2014 & $\begin{array}{l}\text { PIEDADE, } \\
\text { João; PEDRO, } \\
\text { Neuza. }\end{array}$ & $\begin{array}{l}\text { Analisar o índice de } \\
\text { utilização das tecnologias } \\
\text { digitais (TD) nas práticas }\end{array}$ & $\begin{array}{l}\text { Investigação empírica, } \\
\text { pós-positivista, de } \\
\text { natureza quantitativa }\end{array}$ & $\begin{array}{l}\text { Apesar dos scores favoráveis de } \\
\text { proficiência e utilização das mesmas nas }\end{array}$ \\
\hline
\end{tabular}


Rev. Dimensão, Maceió, v. 5. n. 2, p. 21-30, jan/mar, 2021

\begin{tabular}{|c|c|c|}
\hline $\begin{array}{l}\text { e necessidades de } \\
\text { formação dos } \\
\text { diretores escolares } \\
\text { em Portugal. }\end{array}$ & $\begin{array}{l}\text { de gestão escolar e o } \\
\text { sentido de autoeficácia na } \\
\text { utilização das mesmas, } \\
\text { apresentados } \\
\text { diretores escolares. }\end{array}$ & $\begin{array}{l}\text { práticas profissionais, os diretores } \\
\text { referem importantes } \\
\text { necessidades de formação. }\end{array}$ \\
\hline
\end{tabular}

Fonte: Próprio autor. 
Verificou-se que o ano de 2020 foi o que teve mais publicações (2), seguido por 2018, 2017 e 2014 com (1) cada.

Quanto a nacionalidade, três artigos foram brasileiros, (2) Região Sudeste (Bolema - SP, Ensaio: aval. Pol. Publ. Educ. - RJ) e (1) da Região Centro-Oeste (Interações - MS) e (2) internacionais de Portugal (Da investigação às práticas Lisboa e Revista Portuguesa de Educação).

A metodologia adotada pelos (5) artigos, (4) tiveram abordagem qualitativa e (1) abordagem quantitativa; sendo (3) projetos de intervenção, (1) pesquisa exploratória e (1) revisão bibliográfica.

Por fim, para a construção desta revisão sistemática, sintetizou-se o assunto para a formulação das categorias apresentadas a seguir:

\section{Categoria 1 - Os desafios enfrentados pelos gestores para o uso das tecnologias no ambiente escolar}

Em seu estudo a respeito da implantação de um programa federal no Estado de Goiás para a inclusão social por meio das tecnologias de informação, Echalar e Peixoto (2017) destacaram que a finalidade não foi alcançada, porque a real intenção não coibiu a exclusão, e, isto se dá porque o ambiente escolar encontra-se carente de infraestrutura e a própria estrutura do programa não enfrenta a situação real do problema, que deveria estar relacionada a uma formação contínua e producente de professores e alunos. Além disto, os professores acabaram sendo os únicos responsabilizados pelas falhas que resultam na exclusão digital. Para os autores, é preciso ouvir todos os participantes da escola em suas diferentes hierarquias, além de fornecer uma formação continua, avaliativa e apoiadora para a real transformação da realidade de exclusão, característica de uma concepção capitalista.

Para Wichnoski (2020), que buscou verificar os obstáculos que surgiam da prática de ensino de professores de matemática do Paraná, os entraves surgem dos participantes do processo, professoraluno, que se relacionam aos aspectos inerentes destes, aos desafios da disciplina, da própria estrutura escolar e dos obstáculos pertinentes a inserção das TICs que são elucidados pelas concepções dos professores, alunos, da gestão escolar, da equipe pedagógica, da família, especialmente pela rigidez do currículo que dificulta a adoção de metodologias ativas, exigindo de todos um malabarismo para contornar tais problemas que se esbarram na necessidade de uma formação inicial e continuada diferenciada.

Sobre as implicações de tecnologia digital na gestão escolar, tendo como plano de fundo o Programa Jovem do Futuro que proporciona uma relação entre o público e o privado, Balduino (2020) infere que o 
programa traz para o ensino público a lógica de mercado e acaba por responsabilizar as escolas pelos resultados, o que interfere diretamente nas propostas pedagógicas, não respeitando as realidades diversas desse ambiente, comprometendo a autonomia da gestão escolar que consequentemente fere o princípio de gestão democrática, visando alcançar a formação de futuros trabalhadores que venham a suprir as necessidades do setor privado.

\section{Categoria 2 - Os benefícios do uso das tecnologias para o aprimoramento da gestão escolar}

Ao buscarem investigar a incidência do uso de tecnologias digitais (TDs) nas práticas de gestão em escolas públicas de Portugal, durante um ano letivo, Piedade e Pedro (2014) verificaram médias favoráveis que apontaram a auto eficácia destes na utilização das TDs e maior ainda o uso efetivo destas na realização de suas atividades laborais. Todavia, no que se refere ao uso das TDs no campo da comunicação entre os sujeitos da educação, houve uma redução, o que mostra a necessidade de se voltar para este aspecto com o intuito de estimulá-lo, sendo necessário, por parte dos gestores escolares, investir em formação voltada eles mesmos, para que possam efetivamente implementar as TDs em seu ambiente escolar. Para os diretores, existem fatores importantes que favorecem a integração das TDs no espaço escolar, tais como: professores motivados, valorizados, com espirito inovador, diversidade de softwares, entre outros, sendo as práticas docentes o caminho mais efetivo para integrar as tecnologias no ambiente escolar.

Nesta mesma perspectiva, Carlos, Pombo e Loureiro (2018) buscaram demonstrar os resultados obtidos a partir da implantação do conceito de Edulab, voltado para a adoção de práticas pedagógicas inovadoras e o uso de da tecnologia digital pelos professores e alunos. Os autores evidenciaram mudanças significativas nos professores em suas práticas, partindo do princípio da adoção para a adaptação às TICs, agregando as suas aulas dinamismo, eficiência e motivação com importantes contribuições para aprendizagens ativas e significativas, aprimorando as práticas pedagógicas dos professores no que diz respeito ao uso das TDs. O objetivo foi satisfatoriamente alcançado porque o foco não se restringiu a apenas introduzir as TDs na sala de aula, mas principalmente, por focar na formação e apoio aos docentes, assim como na avaliação da influência das TDS no processo de ensino-aprendizagem, tornando possível modificar e otimizar as estratégias pedagógicas, estendendo a duração e a abrangência do programa por um longo período. 


\section{CONCLUSÕES}

Com a realização desta revisão sistemática e a elaboração das categorias que compuseram este trabalho, evidenciouse a existência de importantes desafios para a implantação eficiente das tecnologias no ambiente escolar, seja ela qual for, especialmente quando estas são direcionadas à gestão, observando-se uma importante escassez de artigos sobre o tema. Esta realidade se dá, muito provavelmente, porque o gestor (diretor) escolar é, antes de mais nada, um professor e os desafios enfrentados se esbarram na necessidade de se priorizar uma formação continuada,

\section{REFERÊNCIAS}

BALDUINO, M. A.C. Programa Jovem de futuro: uma tecnologia educacional do terceiro setor. INTERAÇÕES, Campo Grande, MS, v. 21, n. 2, p. 233-243, abr./jun. 2020.

CARLOS, V.; POMBO, L.; LOUREIRO, M. J. Integração pedagógica das TIC no contexto de um Edulab - reflexão e sistematização de boas práticas (Projeto AGIRE). Da investigação às práticas, v.8, n.1, p. 22-41, 2018.

ECHALAR, A. D. L. F.; PEIXOTO, J. Programa um computador por aluno: o acesso às tecnologias digitais como estratégia para a redução das desigualdades sociais. Ensaio: aval. pol. públ. Educ., Rio de Janeiro, v.25, n. 95, p. 393-413, abr./jun. 2017.

FADEL, L. M. et al. Gamificação na educação. São Paulo: Pimenta Cultural, 2014. voltada para o uso das tecnologias em associação com a prática pedagógica.

Faz-se necessário investir em infraestrutura, aliada, prioritariamente, ao processo pedagógico que busque incorporar estas ferramentas ao processo de ensinoaprendizagem. Todas as tecnologias são válidas e fundamentais e precisam estar alinhadas a soberania do processo educativo, tendo como foco principal os seus agentes que precisam sempre ser valorizados e contemplados. Neste contexto, é imprescindível a realização de mais estudos sobre o tema para que se possa discutir e buscar soluções eficientes.

FONTE, M. B. G. Tecnologia na escola e formação de gestores. Dissertação [Mestrado], Programa de Pós-Graduação em Educação. Pontifícia Universidade Católica de São Paulo, Brasil, 2004.

MORAN, J. M.; MASETTO, M.; BEHRENS, M. Novas tecnologias e mediação pedagógica. $7^{a}$ ed. São Paulo, SP.: Papirus, 2003.

PIEDADE, J.; PEDRO, N. Tecnologias digitais na gestão escolar: práticas, proficiência e necessidades de formação dos diretores escolares em Portugal.

Revista Portuguesa de Educação, v.27, n.2, p.109-33, 2014.

WICHNOSKI, Paulo. Obstáculos emergentes da prática de ensino com a investigação matemática. Bolema, Rio Claro (SP), v. 34, n. 67, p. 604-627, ago. 2020. 